\title{
ON THE FORMATION \\ OF THE F1 LAYER DURING SUDDEN STRATOSPHERIC WARMING EVENTS
}

N.M. Polekh

Institute of Solar-Terrestrial Physics SB RAS, Irkutsk, Russia, polekh@iszf.irk.ru

M.A. Chernigovskaya

Institute of Solar-Terrestrial Physics SB RAS, Irkutsk,Russia,cher@iszf.irk.ru

\section{O.E. Yakovleva}

Institute of Solar-Terrestrial Physics SB RAS, Irkutsk, Russia,yakovleva@iszf.irk.ru

\begin{abstract}
Using vertical sounding data obtained by the Irkutsk digisonde DPS-4 from 2003 to 2016, we have studied the frequency of occurrence of the F1 layer in winter conditions. The frequency of occurrence of the F1 layer in December-January is shown to be more than twice lower than that in February at any level of magnetic activity. At moderate and low solar activity under quiet geomagnetic conditions, the appearance of F1 layer in midlatitudes of the Northern Hemisphere may be caused by active thermodynamic processes, which lead to transformation or destruction of the circumpolar vortex at heights of the middle atmosphere. Such global dynamic changes occurring in the winter stratomesosphere are often associated with sudden strato-
\end{abstract}

spheric warming events, which are accompanied by increased generation of atmospheric waves of various scales. These wave disturbances can propagate upward to the heights of the lower thermosphere and ionosphere, carrying a significant vertical flow of energy and causing variations in the composition, thermodynamic parameters of the neutral atmosphere and ionosphere.

Keywords: ionosphere, low atmosphere, stratospheric warming, F1 layer.

\section{INTRODUCTION}

The F1 layer is observed only in the daytime, mainly at low solar activity and small solar zenith angles. It is therefore recorded very rarely in winter at high solar activity, and the degree of its development varies greatly during the day [Polyakov et al., 1968; Ivanov-Knolodny, Nikolsky, 1969; Brunelli, Namgaladze, 1988]. Figure 1 presents ionograms (height-frequency characteristics) illustrating the occurrence of the F1 layer in winter. The ionograms were obtained by the DPS-4 digisonde and processed using the interactive software SAO-Explorer [Khmyrov et al., 2008]. Figure 1 shows that on December 22, 2009 the F1 layer looks like a bend of track on the ionogram, and on January 2, 2006 all the tracks corresponding to reflections from the E, F1, and F2 layers are well-defined.

Below the F1-layer maximum height $\left(h_{\mathrm{m}} \mathrm{F} 1\right)$, the layer mainly consists of ions $\mathrm{NO}^{+}$and $\mathrm{N}_{2}^{+}$with admixtures of ions $\mathrm{O}_{2}^{+}$and $\mathrm{O}^{+}$. Above $h_{\mathrm{m}} \mathrm{F} 1$, the $\mathrm{O}^{+}$ion density first becomes comparable with the $\mathrm{NO}^{+}$and $\mathrm{N}_{2}^{+}$densities, and then, when the height increases, it becomes greater than the molecular ion density. Consequently, the F1 layer is formed under conditions when the transition from the predominance of molecular ions $\left[\mathrm{M}^{+}\right]$, i.e. $\left[\mathrm{NO}^{+}\right]$and $\left[\mathrm{O}_{2}^{+}\right]$, to the predominance of atomic ions $\left[\mathrm{O}^{+}\right]$(or the transition from the square law of electron losses to the linear one) occurs above the height of the $\left[\mathrm{M}^{+}\right]$density maximum. Thus, the F1-layer development is determined by the height ratio of the $\left[\mathrm{O}^{+}\right]$and $\left[\mathrm{M}^{+}\right]$ densities: the lower is the ratio $\left[\mathrm{O}^{+}\right] /\left[\mathrm{M}^{+}\right]$, the better is the development of the F1 layer. Consequently, the gas composition change plays an important role in the formation of the F1 layer.
As follows from the analysis of photochemical processes [Ivanov-Kholodny, Nikolsky, 1969; Brunelli, Namgaladze, 1988], the cycle of reactions leading to the formation of the F1 layer is associated with the temperature regime of the lower thermosphere. Its variations cause a change in the rate of recombination processes, which can alter concentrations of the main components of the thermosphere. The ratio between $[\mathrm{O}] /\left[\mathrm{N}_{2}\right]$ and $[\mathrm{O}] /\left[\mathrm{O}_{2}\right]$ decreases from winter to summer, and this explains why the F1 layer appears predominantly in summer [Brunelli, Namgaladze, 1988]. An increase in geomagnetic activity also causes the ratio $[\mathrm{O}] /[\mathrm{M}]$ to decrease at high and middle latitudes (thus causing negative ionospheric disturbances in the F2-region [Prölss, 1987; Buonsanto, 1999; Danilov, Laštovička, 2001]) and generates conditions under which the electron density at F1-layer heights becomes higher than at the F2-layer maximum (condition G) [Buresova, Laštovička, 2001; Deminov et al., 2011a; Polekh et al., 2015].

A sudden stratospheric warming (SSW) is a significant large-scale meteorological phenomenon that occurs in the high-latitude winter stratosphere.

During SSW for several days or even weeks in the polar stratosphere there is an increase in temperature accompanied by a significant drop in the zonal wind (weak, or minor SSW) or even by a change in its direction from westward to eastward (strong, or major SSW). A large body of research devoted to the experimental study of the impact of SSW on parameters of the neutral atmosphere and ionosphere has shown that thermodynamic perturbations during major SSW occur not only 

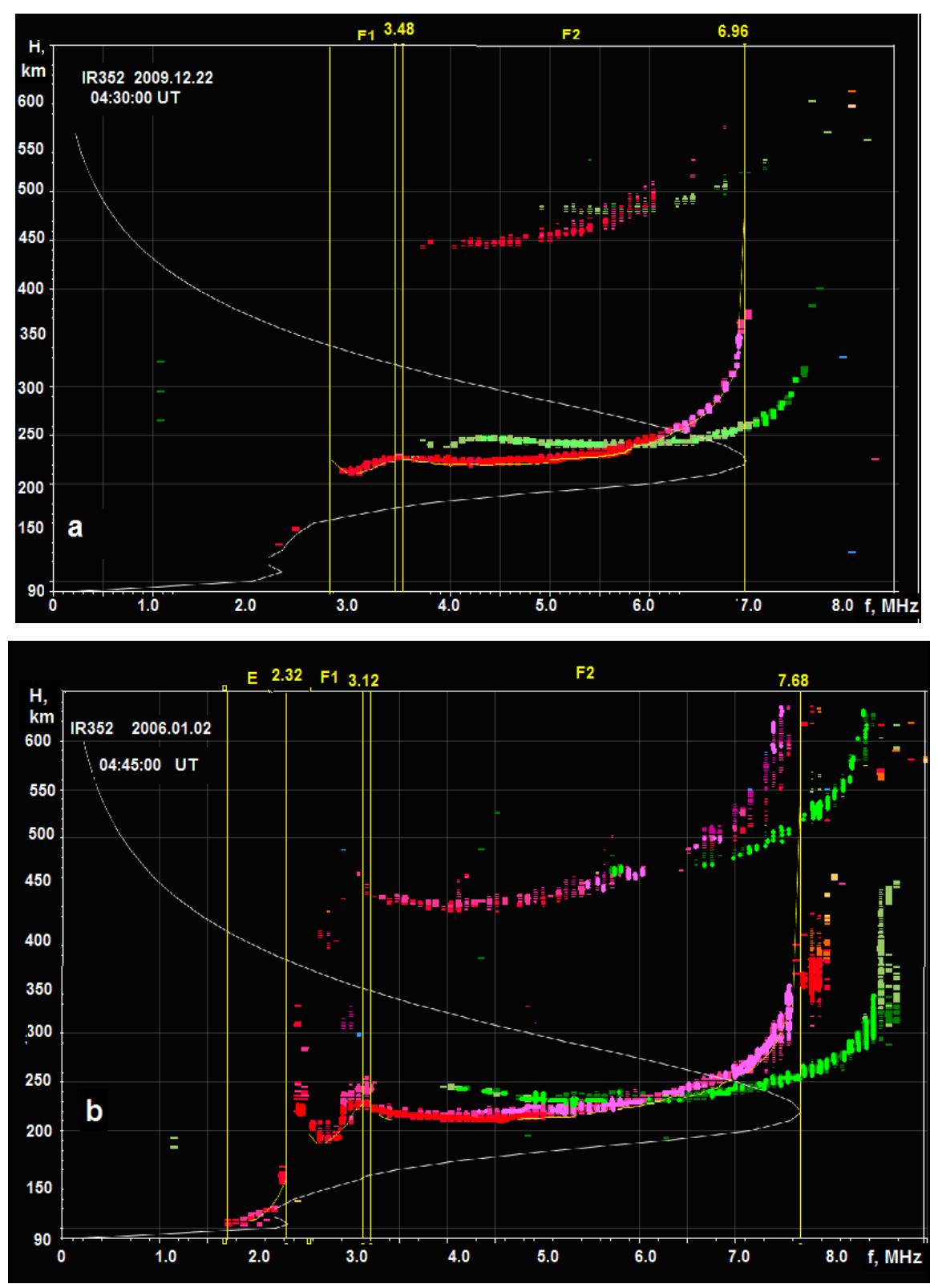

Figure 1. Ionograms illustrating different types of F1-layer development over Irkutsk: on December 22, 2009 at 04:30 UT (a); on January 02, 2006 at 04:45 UT (b). LT=UT+7. The dashed line shows the calculated electron density profile

in the stratosphere. They cover a wide range of altitudes and are recorded both in the polar zone and in middle and equatorial latidudes [Funke et al., 2010; Pedatella, Forbes, 2010]. These perturbations manifest themselves in changes of velocities of horizontal and vertical winds [Hocke et al., 2015], in variations of parameters of oxygen and hydroxyl molecule emissions [Fishkova, 1978; Medvedeva et al., 2012; Medvedeva, Ratovsky, 2018]. The SSW related perturbations have been found in variations of critical frequencies and peak heights [Pancheva, Mukhtarov, 2011; Sumod et al., 2012; Shpynev et al., 2015a; Chernigovskaya et al., 2018b], ionic temperatures [Goncharenko, Zhang, 2008], total electron content (TEC) [Goncharenko et al., 2010a, b; Polyakova et al., 2014; Chernigovskaya et al., 2018a], etc. Semidiurnal harmonics have been shown to be enhanced during SSW, leading to an increase in night values of the electron density and TEC.
Furthermore, Shpynev et al. [2015b], Chernigovskaya et al. [2018b] have shown that variations in ionospheric parameters observed at different longitudes in the Northern Hemisphere essentially depend on positions of ionosondes relative to structures of the prevailing strato-mesospheric circulation. The difference in F2-layer critical frequencies for ionosondes spaced longitudinally by $15-20^{\circ}$ can be as large as 1.5-2 MHz.

This paper studies the occurrence of the F1 layer in winter and the possible effect of stratospheric warming events on its formation under quiet geomagnetic conditions.

\section{EXPERIMENTAL DATA ANALYSIS}

The analysis relies on results of manual processing of vertical sounding data acquired by the digisonde DPS-4, 
located in Irkutsk $\left(52.5^{\circ} \mathrm{N}, 104^{\circ} \mathrm{F}\right)$, with a 15 -min resolution during winter months (December-February) of 2003-2016. Altitude-time temperature distributions in the strato-mesosphere over Irkutsk were obtained from measurements made with a Microwave Limb Sounder (MLS) on board the EOS Aura spacecraft. The MLS/Aura data on temperature is presented as vertical profiles from the ground level to an altitude of $10^{-5} \mathrm{hPa}$ (0-130 km) [https://mls.jpl.nasa.gov/products/temp_ product.php].

The frequency of occurrence of the F1 layer was estimated as the ratio of the number of recordings of the F1 layer to the total number of sounding sessions in a given month (in \%). In Figure 2 are histograms of occurrence of the F1 layer in winter months by years. We took into account all cases of occurrence of the F1 layer, even when it was not clearly formed and was seen on an ionogram as a bend of track (see Figure 1, $a$ ). Referring to Figure 2, in February the frequency of occurrence of the F1 layer is 2-3 times higher than that in DecemberJanuary, mainly due to the increase in the duration of daylight. In the last decade of February, the F1 layer is recorded more often, and the duration of its registration increases regardless of the level of magnetic activity (Figure 3).

The appearance of the F1 layer in DecemberJanuary during years of high and medium solar activity is usually caused by the increased level of magnetic activity (Figure 2), although it occasionally occurs under quiet geomagnetic conditions around midday. The frequency of occurrence of the F1 layer may be assumed to be associated with variations of ionospheric parameters during the development of winter stratospheric warming events when a global change in the thermodynamic regime of the underlying atmosphere

a
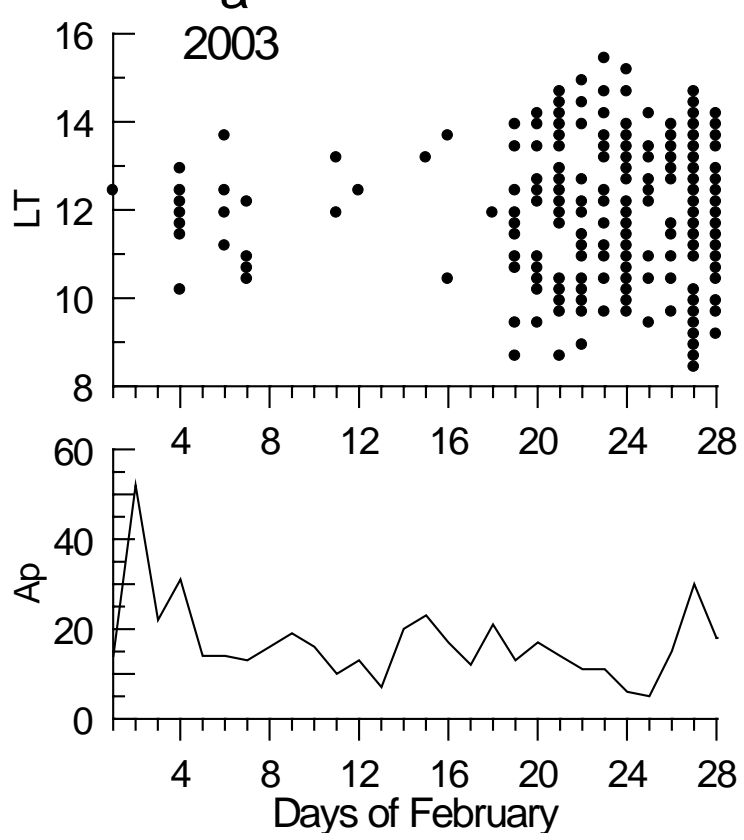
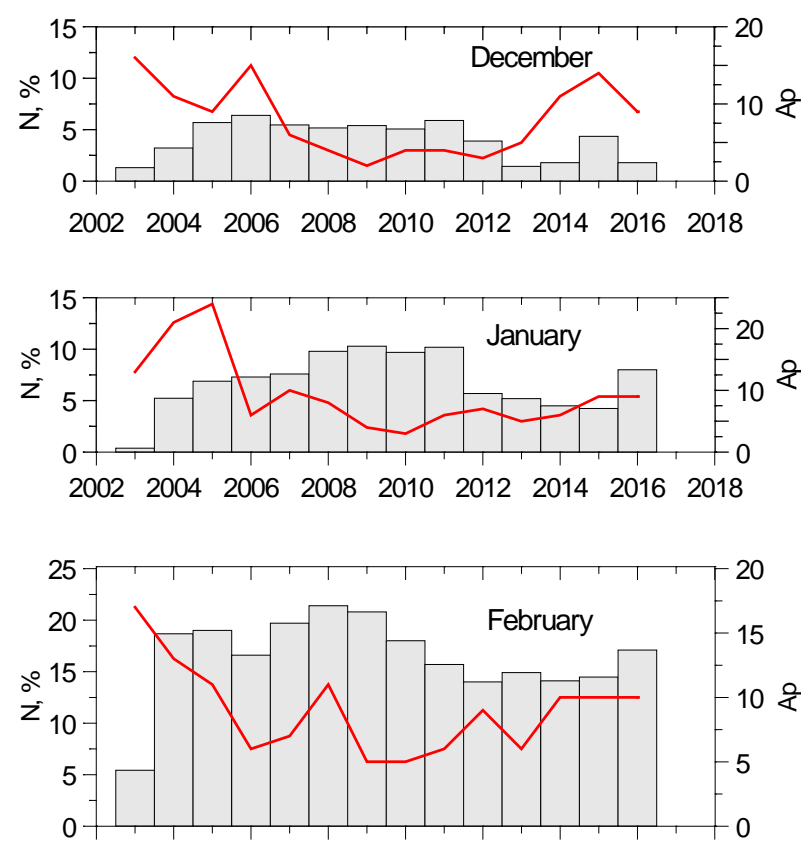

200220042006200820102012201420162018

Figure 2. Histograms of the occurrence of the F1 layer in winter by years. The red line shows the monthly average $A_{\mathrm{p}}$ index

takes place. To illustrate the effect of magnetic disturbance level and daylight duration on conditions of the F1-layer formation, we consider the local time (LT) of its occurrence in February 2003 and February 2010 (see Figure 3). In February 2003, there was no stratospheric warming, and the isolated cases of F1layer recording in the first half of February are associated with a change in thermospheric composition during magnetic disturbances. In 2010, SSW developed

b
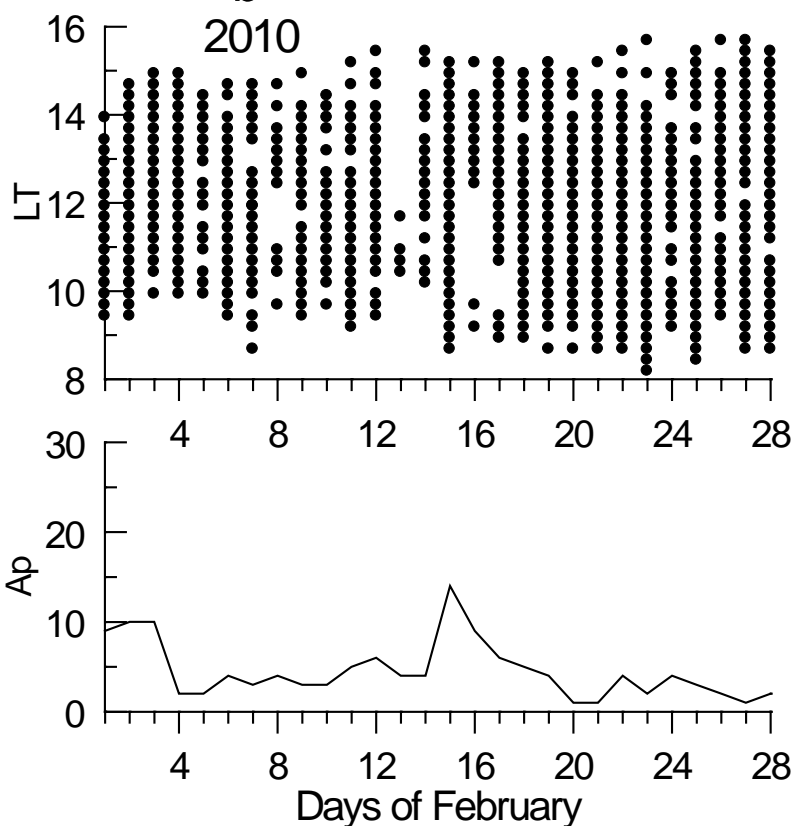

Figure 3. Frequency of occurrence of the F1 layer in February: 2003 (a); 2010 (b) 
The comparison of Figure 3, $a$ and $b$ shows that with SSW developing under quiet geomagnetic conditions the frequency of occurrence of the F1 layer significantly increased in the first half of February 2010. By the last decade of February, the duration of daylight increased, thus increasing the probability of occurrence of the F1 layer. In what follows, we therefore use data only for two winter months - December and January. To eliminate the influence of disturbed conditions on the frequency of F1-layer occurrence, we analyze only the warming events that occurred during geomagnetically quiet and weakly disturbed periods.

\section{Winter of 2005-2006.}

The stratospheric warming in the winter of 2005-2006 was strong. From mid-December, the average velocity of the stratospheric zonal wind at a latitude of $60^{\circ} \mathrm{N}$ began to decrease rapidly and changed its direction from westward to eastward in late January - early February. The maximum velocity of the easterly wind was as high as $33 \mathrm{~m} / \mathrm{s}$ [http://www.cpc.ncep.noaa.gov/products/stratosphere/strattrop].

Figure 4, $a$ depicts the altitude-time temperature variations in the middle atmosphere at $10-100 \mathrm{~km}$ over the Irkutsk region. The maximum temperature increase (295 K) was observed at $46 \mathrm{~km}$ on December 31, 2005. The middle panel of Figure $4, b$ presents variations of the auroral $A E$ index and mid-latitude planetary $K_{\mathrm{p}}$ index. We can see that in this interval before the onset of the stratospheric temperature maximum there was an ionospheric disturbance generated by the weak magnetic storm on December 27 with a minimum Dst index of $39 \mathrm{nT}$. This storm had a long recovery phase - to January 1,2006 . The solar activity index $F 10.7$ (solar radio flux at $10.7 \mathrm{~m}, 10^{-22} \mathrm{~W} /\left(\mathrm{m}^{2} \mathrm{~Hz}\right)$ ) varied slightly from 80.6 to 89.5. Figure 4, $c$ presents variations in critical frequencies of the $\mathrm{F} 2$ and $\mathrm{F} 1$ layers $\left(f_{0} \mathrm{~F} 2\right.$ and $f_{0} \mathrm{~F} 1$ respectively) from December 26, 2005 to January 5, 2006 (i.e. 5 days before and after the onset of the stratospheric temperature maximum). The blue line illustrates variations in the running median of $f_{0} \mathrm{~F} 2$, calculated by 15 days and centered on a given date. The choice of the 15day interval for calculating the median is justified in [Deminov et al., 2011b]. Figure 4, $c$ shows that from December 27 the averaged near-noon values of $f_{0} \mathrm{~F} 2$ (04-06 UT) exceeded the corresponding medians. The values of $f_{\mathrm{o}} \mathrm{F} 2$ calculated for near-midnight hours (16-19 $\mathrm{UT}$ ) were lower than the median ones. After December 28, night values of $f_{0} \mathrm{~F} 2$ increased overall by $0.3-0.5 \mathrm{MHz}$.

The F1 layer was occasionally recorded in this interval. It is difficult to say unequivocally what caused the formation of the F1 layer. It might have been due to the superposition of two effects: ionospheric disturbances driven by a magnetic storm and a stratospheric warming in the underlying atmosphere. We can assume that the increase in daytime critical frequencies was caused by positive ionospheric disturbances characteristic of winter mid-latitude ionospheric storms. The increase in nighttime critical frequencies may be attributed to the enhancement of the SSW-induced semidiurnal harmonic.
The second part of the interval (January 1-5) was characterized by quiet geomagnetic conditions. During these five days, positive deviations were also recorded during daylight hours, the greatest ones observed for 3 days after the onset of the stratospheric temperature maximum. The next day, daytime $f_{0} \mathrm{~F} 2$ slowly decreased to median values and were lower than the median values on January 4-5. Maximum increases in nighttime $f_{0} \mathrm{~F} 2(\sim 0.8-0.9 \mathrm{MHz})$ relative to the median occurred on January 1 and 5 .

A decrease in $h_{\mathrm{m}} \mathrm{F} 2$ relative to median values was observed. These variations in $f_{0} \mathrm{~F} 2$ and $f_{0} \mathrm{~F} 1$ bear witness to fluctuations of critical frequencies with periods of several days. Note that the F1 layer with 2.8-3.4 MHz frequencies was recorded most often on January 2 and 3 , and the peak height ranged from 145 to $163 \mathrm{~km}$.

\section{Winter of 2008-2009.}

The stratospheric warming in the winter of 20082009 was one of the most intense and sustained events. Since the warming occurred at an extremely low level of solar activity and under quiet geomagnetic conditions, this time interval is the most favorable for studying the influence of processes in the underlying atmosphere on the distribution of ionospheric parameters [Pedatella, Forbes, 2010; Shpynev et al., 2013; Chernigovskaya et al., 2015 and references therein].

The top panel of Figure 5 shows altitude-time temperature variations in the middle atmosphere for the Irkutsk region at $10-100 \mathrm{~km}$ from December 1 to December 27, 2008. We can see that on December 7 there was an increase in the stratospheric temperature to $292.6 \mathrm{~K}$ at $46 \mathrm{~km}$. The $A E$ index did not exceed $200 \mathrm{nT}$, and the three-hour $K_{\mathrm{p}}$ index was less than 2 on December 8-16, except for the last six hours on December 16 when its value was as large as $3-$ (Figure $5, b$ ).

The solar activity index $F 10.7$ ranged from 66.4 to 68.7. The bottom panel shows $f_{\mathrm{o}} \mathrm{F} 1$ and $f_{\mathrm{o}} \mathrm{F} 2$ variations and values of the running median of $f_{0} \mathrm{~F} 2$. The sharp fluctuations of critical frequencies registered in the near-noon hours were generated by traveling ionospheric disturbances (TIDs). On ionograms, additional cusps were pronounced near the F2-layer critical frequency. Values of $f_{\mathrm{o}} \mathrm{F} 1$ ranged from 2.78 to $3.56 \mathrm{MHz}$; layer maximum heights, from 144 to $196 \mathrm{~km}$. The maximum deviations of the daytime $f_{0} \mathrm{~F} 2$ values from their medians were observed on December 8, i.e. the next day after the onset of the stratospheric temperature maximum, and the largest deviations during nighttime hours were registered on December 12-13.

\section{Winter of 2012-2013}

The temperature and dynamic regime of the stratospheric warming in the winter of 2012-2013 has been studied in detail by Vargin and Medvedeva [2015]. This stratospheric warming occurred under high solar activity conditions. The authors have established that the first temperature rise was on December 23-26, then, at the beginning of January, the temperature rose further by $\sim 20 \mathrm{~K}$ and remained above the mean climatic one by 10 $20 \mathrm{~K}$ in January. After the onset of temperature maximum 

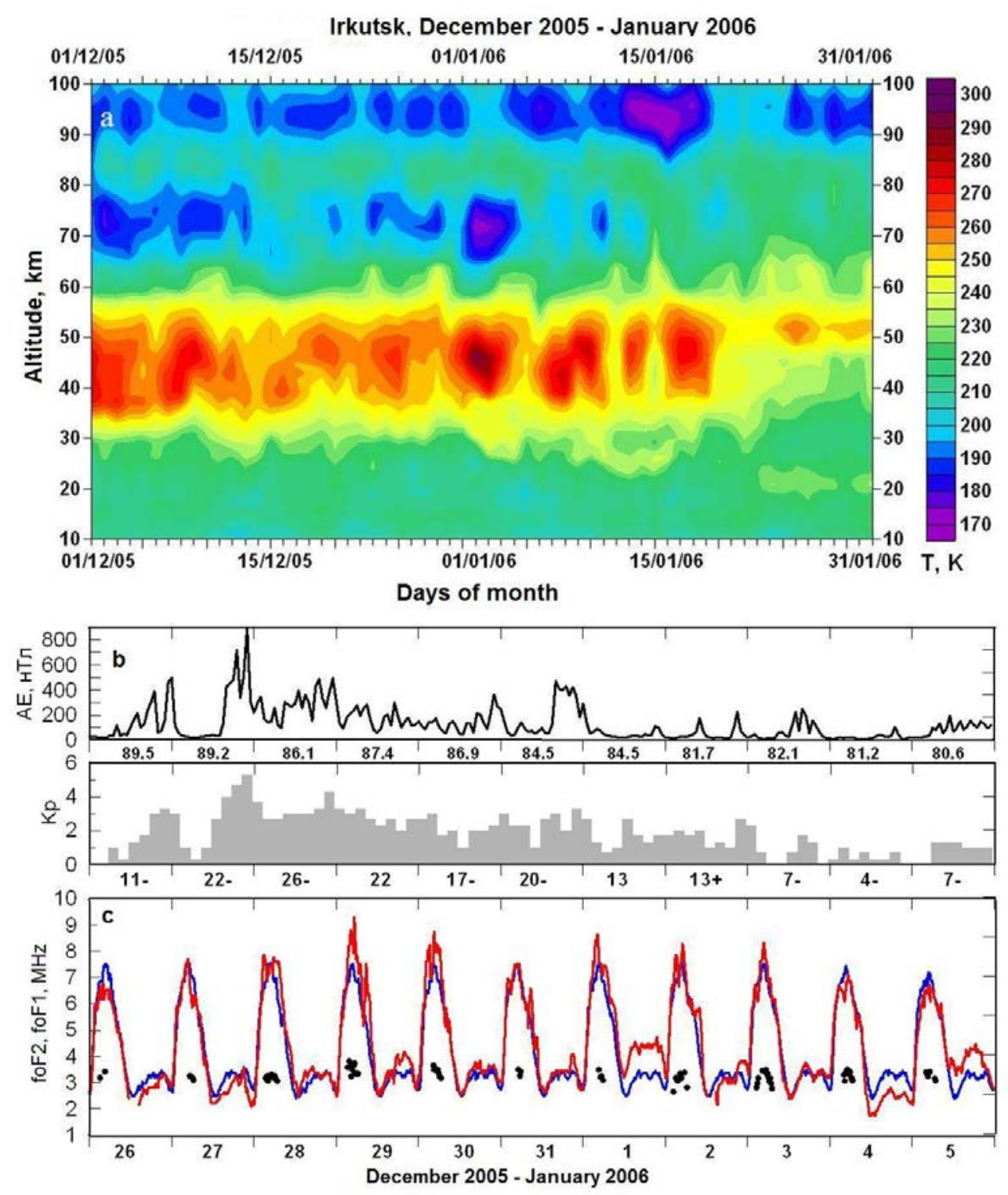

Figure 4. Map of altitude-time temperature distribution in the middle atmosphere at 10-100 km (a) in December 2005 - January 2006; variations in $A E, K_{\mathrm{p}}(b)$ and $f_{\mathrm{o}} \mathrm{F} 2$ (red line), $f_{\mathrm{o}} \mathrm{F} 1$ (circles) on December 26, 2005 - January 5, 2006 (c). The blue line indicates the course of median values of $f_{\mathrm{o}} \mathrm{F} 2$. Under the plot of the $A E$ index $(b)$ are values of the solar activity index $F 10.7, K_{\mathrm{p}}$ index — the summary $K_{\mathrm{p}}$ index for these days

on January 5-6, 2013, the meridional temperature gradient between the pole and the $60^{\circ} \mathrm{N}$ latitude changed, the zonal wind changed its direction from westward to eastward, and the polar vortex split into two parts in the lower and middle stratosphere. Vargin and Medvedeva [2015] have shown that the main SSW phase was preceded by enhancement of wave activity fluxes from the troposphere to the stratosphere in late November, on December 21-25, and at the beginning of January 2013. We have therefore examined two intervals of occurrence of the F1 layer: December 18-31, 2012 and January 1-12, 2013.

Figure 6 illustrates altitude-time variations in temperature of the middle atmosphere $(a)$, in geomagnetic indices $(b)$, and in $f_{0} \mathrm{~F} 1$ and $f_{0} \mathrm{~F} 2(c)$ on December 18 31, 2012. The F10.7 index ranged from 104.2 to 112.4. Against the background of relatively quiet geomagnetic conditions on December 18 and 20, bursts of the $A E$ index to 280 and $536 \mathrm{nT}$ respectively were detected, and the planetary $K_{\mathrm{p}}$ index increased to $2+$ and 3 (Figure 6, $b)$. In general, in this time interval the F1 layer was detected much less often than in the winter of 2008, and the time of its detection was limited to noon hours (1213 LT) (see Figure 6, c). During the first two days (December 18 and 19), daily values of $f_{0} F 2$ were higher than the median ones, and the F1 layer with critical frequencies 3.6-3.8 MHz was observed quite often. On the following days, to December 25, daytime critical frequencies decreased, and the F1 layer was recorded much less often. At night, critical frequencies differed slightly from the respective median values.

On December 26-31, geomagnetic conditions were quiet. At night, $f_{\mathrm{o}} \mathrm{F} 2$ variations differed significantly from variations of median values: the greatest deviations of 

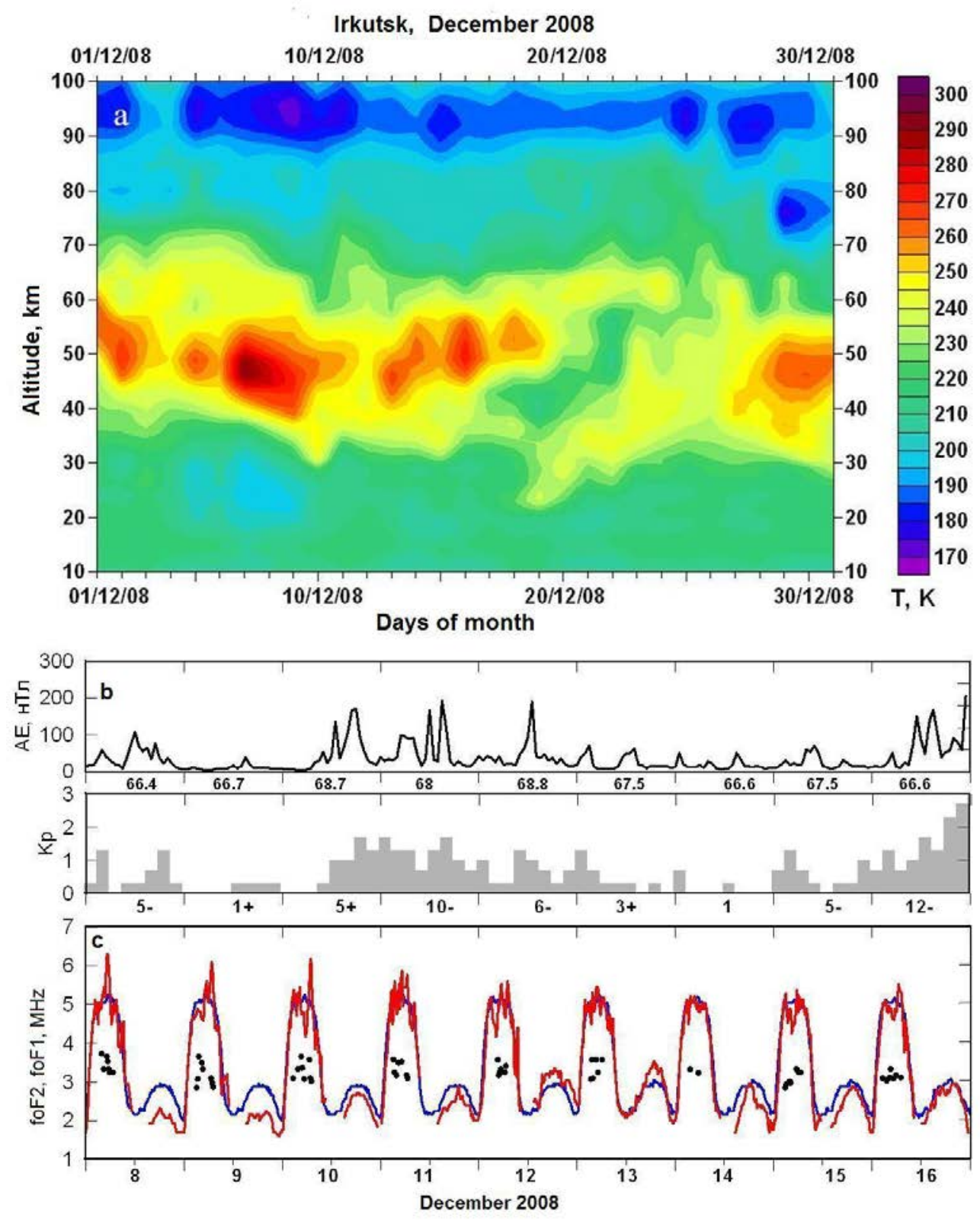

Figure 5. Map of altitude-time temperature distribution in the middle atmosphere at 10-100 km in December 2008 (a); variations in $A E, K_{\mathrm{p}}(b)$ and in $f_{\mathrm{o}} \mathrm{F} 2, f_{\mathrm{o}} \mathrm{F} 1$ from December 8 to December 16, $2008(c)$. Notations are the same as in Figure 4

midnight $f_{\mathrm{o}} \mathrm{F} 2$ from the corresponding medians were $\sim 0.6-0.75 \mathrm{MHz}$. The F1 layer was recorded most often from December 25 to December 31. This coincided with an increase in $f_{\mathrm{o}} \mathrm{F} 2$. Such $f_{\mathrm{o}} \mathrm{F} 2$ variations were presumably due to the enhancement of wave activity generated by SSW development.

The interval of January 1-12, 2013 (Figure 6, $d, e$ ) includes 5 days prior to the onset of the temperature maximum (January 5-6) and 5 days after it. It was characterized by quiet geomagnetic conditions and an increase in solar activity ( $F 10.7$ increased from 113.9 to 168.2). During the first two days of the interval considered, the current values of $f_{\mathrm{o}} \mathrm{F} 2$ were lower their respective medians both by day and at night (Figure 6, $e$ ). After the onset of the temperature maximum in the stratosphere on January 6-10, daily values of $f_{\mathrm{o}} \mathrm{F} 2$ exceeded the median ones by $0.3-0.4 \mathrm{MHz}$, then they began to decrease. The increase in daytime $f_{\mathrm{o}} \mathrm{F} 2$ might have been caused by the increase in solar activity, but by the end of the period considered (January 11-12) at a sufficiently high solar activity level (F10.7 166.7-163.7) they were by $0.4-0.5 \mathrm{MHz}$ lower than their respective medians. The largest negative deviations of midnight critical frequencies were detected before the onset of the temperature maximum (January 1-2); the positive ones, on January 9. Note that the largest positive deviations of $f_{\mathrm{o}} \mathrm{F} 2$ occurred during predawn hours (04-06 LT). The F1 layer was recorded less often than on December 26-31, only after January 9 it appeared more often.

\section{RESULTS AND DISCUSSION}

Numerous studies of effects of processes in the lower and middle atmosphere on spatio-temporal variations of 
ionospheric parameters during stratospheric warming events have identified a relationship of dynamic parameters of the middle atmosphere with TEC variations and ionospheric parameters at different altitude levels — from the lower ionosphere to the F2-layer maximum height [Goncharenko, Zhang, 2008; Goncharenko et al., 2013; Pancheva, Mukhtarov, 2011; Medvedeva et al., 2012; Shpynev et al., 2013; Hocke et al., 2015; Polyakova et al., 2014; Chernigovskaya et al., 2018a; Chernigovskaya et al., 2018b], etc.

In general, the seasonal formation and damping of intense cyclonic vortices over the Earth pole in the winter hemisphere is the most distinguishing feature of the strato-mesospheric circulation. Strong westerly circumpolar winds forming the stratospheric jet stream at the edge of the polar vortex contrast strikingly with very weak easterly winds in the summer hemisphere. In both the hemispheres, circumpolar vortices (CPV) begin to form in fall when there is no solar heating in polar regions, strengthen in midwinter, and break down in late winter - early spring as sunlight returns to the polar regions [Waugh, Polvani, 2010]. The most common explanation for the occurrence of winter CPV is the temperature gradient that results from differences in radiative cooling inside and outside of this zone in winter. The greater is the temperature difference, the greater are the pressure gradients, and hence the higher are the wind speeds in the stratospheric jet stream.

The main cause of the disturbances in winter CPV leading to its global transformations is generally thought to be Rossby waves [Matsuno, 1971]. They are most effectively generated in the troposphere of the Northern Hemisphere by large temperature gradients due to orographic features of the mainland and uneven heating of the land/sea surface. These large-scale waves propagating upward interact with the prevailing zonal wind and perturb it at stratospheric heights. If the perturbation is sufficiently intense, the stratospheric flux velocity decreases and even changes its direction. In this case, CPV splits into several vortices of cyclonic and anticyclonic types; these vortices shift to midlatitudes [Matsuno, 1971; Yigit, Medvedev, 2015].

Shpynev et al. [2015b; 2016] have examined another physical mechanism of formation of winter CPV, namely, cooling and downwelling of the atmospheric gas during the polar night in the absence of sunlight and thermal energy sources.

Under these conditions, the kinetic energy of the vortex continually increases due to a decrease in the atmospheric gas gravitational potential. At the level of constant pressure, CPV has a structure resembling a whirlpool on the water surface. Inside CPV, conditions for the occurrence of instabilities that generate atmospheric waves of different scales, including internal gravity waves (IGWs), are formed. These waves can propagate upward into the mesosphere and lower thermosphere, carrying a considerable vertical energy flux [Chernigovskaya et al., 2015, 2018b]. At heights of the lower thermosphere, IGWs cause variations in the thermodynamic regime and atmosphere composition, thereby generating variations in ionospheric parameters.
Shpynev et al. [2016] have shown that the molecular gas downwelling from the lower thermosphere to the region of active cyclonic circulation in the mesosphere and stratosphere leads to an increase in $[\mathrm{O}] /\left[\mathrm{N}_{2}\right]$ at thermospheric heights and hence to an increase in the electron density and to a decrease in the height of maximum ionization. Conversely, over the high-pressure area in an anticyclone the molecular gas upwelling from the active circulation region in the stratosphere and mesosphere to heights of the lower thermosphere causes a decrease in $[\mathrm{O}] /\left[\mathrm{N}_{2}\right]$ and, therefore, a decrease in the critical frequency and an increase in the height of maximum ionization.

The results of simulation of atmospheric and ionospheric effects of SSW for conditions in January 2009 represent a picture of increasing temperature and meridional wind speed, decreasing electron density and $[\mathrm{O}] /\left[\mathrm{N}_{2}\right]$ at $300 \mathrm{~km}$ in the Northern Hemisphere during near-noon hours [Bessarab et al., 2012]. Consequently, the SSW-driven disturbances manifest themselves throughout the F-region and can contribute to the appearance of the F1 layer. In future, we plan to calculate the relative change in the thermosphere composition during stratospheric warming events of different intensities, using a semi-empirical model of the F1 layer [Shchepkin et al., 1997].

Wave disturbances also play a significant role in the very process of development of instability by providing feedback through additional heating of overlying atmospheric layers. The analysis of variations in the ionospheric electron density maximum and TEC over Eastern Siberia and Far East from ionosonde and GPS/GLONASS data has revealed an increase in ionospheric variability during SSW [Chernigovskaya et al., 2015; Yasyukevich et al., 2017]. It has been established that there was a marked increase in the high-frequency part of variability in the F2-layer electron density maximum and TEC (during periods ranging from 0.5 to 6 hrs) in winter, which was mainly caused by traveling ionospheric disturbances associated with upward propagating IGW. A significant role of IGWs in forming ionospheric variability during SSW has been confirmed by theoretical calculations [Yigit et al., 2014].

Passage of IGW is followed by changes in peak heights of the F1 and F2 layers. Figure 7, $a, b$ shows $h_{\mathrm{m}} \mathrm{F} 1$ versus $h_{\mathrm{m}} \mathrm{F} 2$ for January $17-22$ and January 2731 during strong SSW in 2009 under quiet geomagnetic conditions. We can see that in the former case $(a)$ there is no correlation (correlation coefficient is 0.3); in the latter $(b)$ the correlation coefficient is higher. Figure $7, c-f$ more readily illustrates time variations in heights of the F1- and F2-layer maxima for the two adjacent dates. The selected dates are also characterized by quiet geomagnetic conditions. It can be seen that in some cases there is a fairly good correlation between these parameters, in other cases there is no correlation. As already mentioned, Shpynev et al. [2016] have shown that variations in ionospheric parameters during SSW depend on positions of ionosondes relative to the prevailing winter jet stream in the strato-mesosphere whose vertical and horizontal velocities can greatly vary during SSW. This contributes 

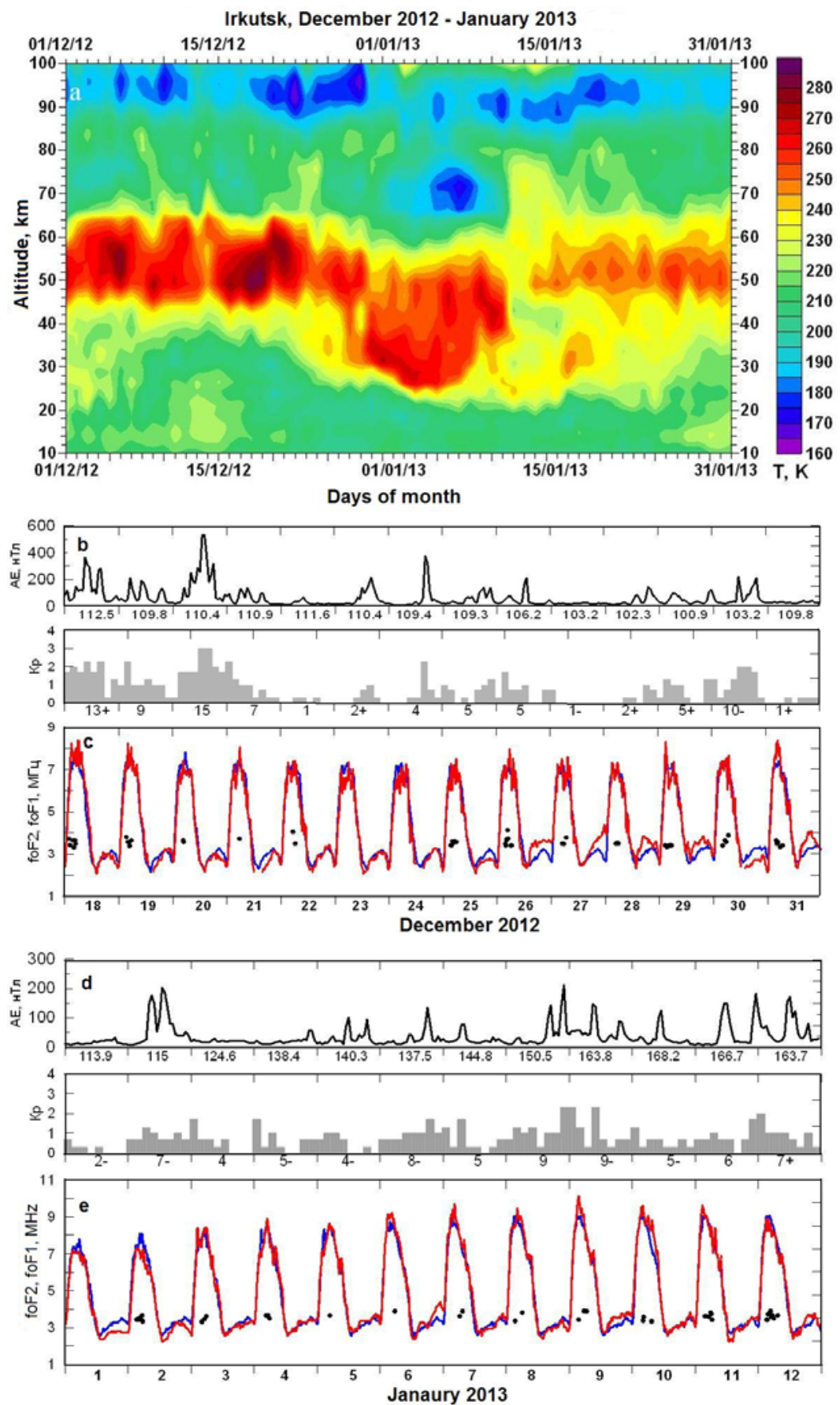

Figure 6. The same as in Figure 5 for December 1, 2012 - January 31, 2013 (a), December 18-31, $2012(b, c)$ and January $1-12,2013(d, e)$

to the generation of IGWs of different time scales, which causes a change in heights of the F1- and F2layer maxima.

\section{CONCLUSIONS}

We have reported the results of the joint analysis of DPS-4 vertical sounding data and MLS/Aura measurements of temperature in the middle atmosphere over the Irkutsk region for the winter months (DecemberFebruary) of 2003-2016.

The frequency of occurrence of the F1 layer in December and January is shown to be more than two times lower than that in February at any level of magnetic activity. The main factor determining the frequency of occurrence of the F1 layer is the duration of daylight.

We think that in middle and subpolar latitudes of the Northern Hemisphere at strato-mesospheric heights the active thermodynamic processes, which lead to transformation or destruction of a circumpolar vortex and to wave activity enhancement in the underlying atmosphere, can contribute to the occurrence of the mid-latitude F1 layer.

The results can be useful for studying electron density variations at altitudes $\sim 150-200 \mathrm{~km}$ and the thermosphere composition during winter stratospheric warming events. 

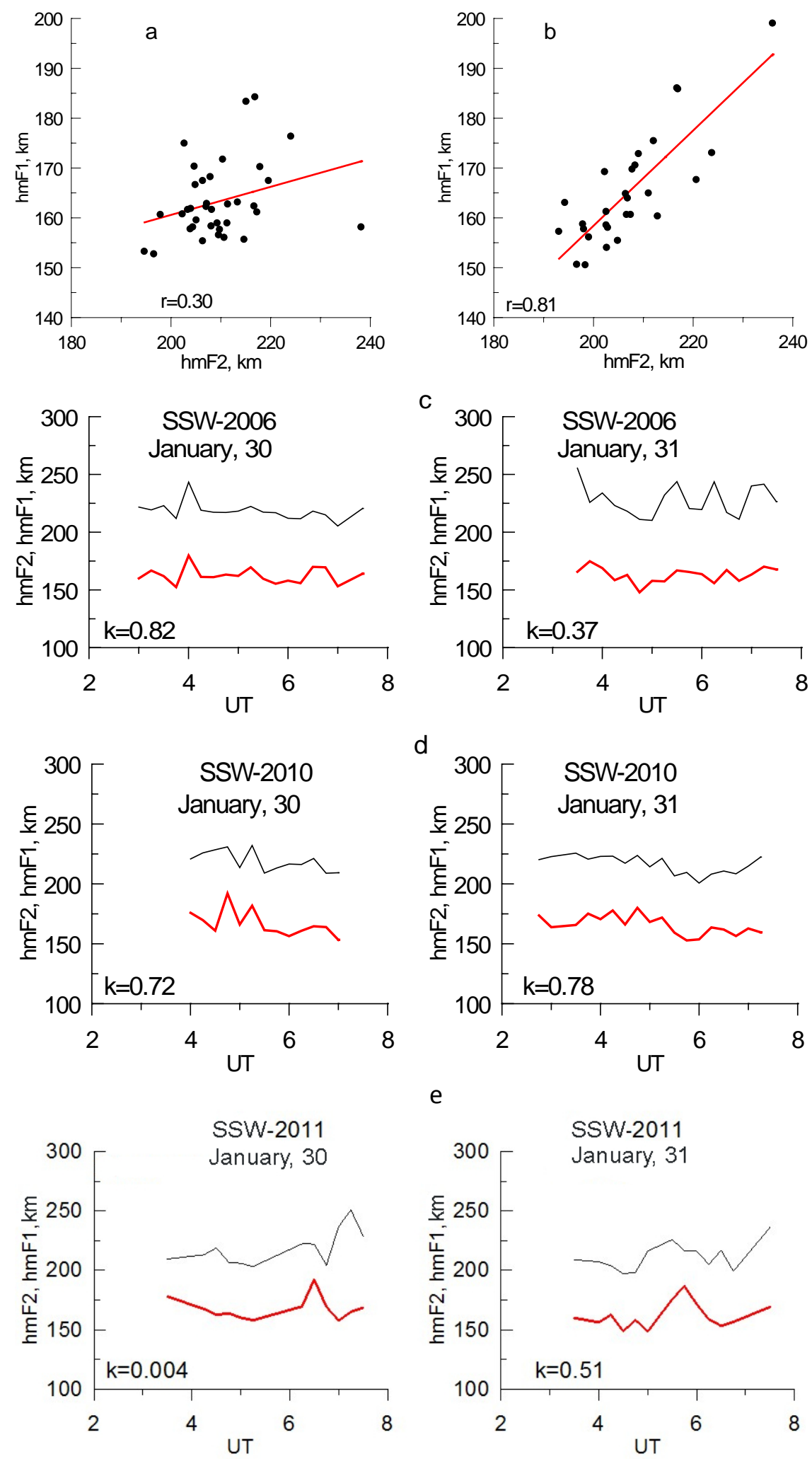

e

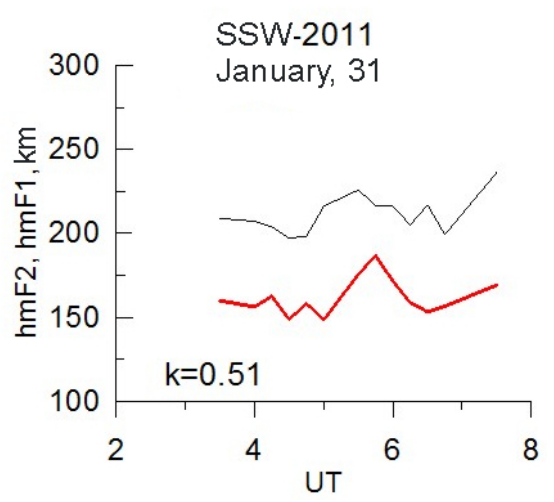

Figure 7. $h_{\mathrm{m}} \mathrm{F} 1$ versus $h_{\mathrm{m}} \mathrm{F} 2$ for January 17-22 (a) and January 27-31, $2009(b) ; h_{\mathrm{m}} \mathrm{F} 1$ (red line) and $h_{\mathrm{m}} \mathrm{F} 2$ (black line) variations with time for two subsequent dates in different years during SSW $(c-e)$

The work was performed with budgetary funding of Basic Research program II.16. The results were obtained using the equipment of Center for Common Use «Angara» [http://ckp-rf.ru/ckp/3056]. Thanks are extended to the European Centre for Medium-Range
Weather Forecasts [https://mls.jpl.nasa.gov/products/ temp_product.php] for the ERA-Interim reanalysis data used in this study. We are grateful to the administration of the website [http://wdc.kugi.kyoto-u.ac.jp/ wdc/Sec3.html] for magnetic data. 


\section{REFERENCES}

Bessarab F.S., Korenkov Yu.N., Klimenko M.V., Klimenko V.V., Karpov I.V., Ratovsky K.G., Chernigovskaya M.A. Modeling the effect of sudden stratospheric warming within the thermosphere-ionosphere system. J. Atmos. Solar-Terr. Phys. 2012, vol. 90-91, pp. 77-85. DOI: 10.1016/j.jastp.2012.09.005.

Brunelli B.E., Namgaladze A.A. Fizika ionosfery [Physics of the Ionosphere]. Moscow, Nauka Publ., 1988. 528 p. (In Russian).

Buonsanto M.J. Ionospheric Storms. A review. Space Sci. Rev. 1999, vol. 88, pp. 563-601.

Buresova D., Lastovicka J. Changes in the F1 region electron density during geomagnetic storms at low solar activity. J. Atmos. Solar-Terr. Phys. 2001, vol. 63, pp. 537-544. DOI: 10.1016/ S1364-6826(00)00167-X.

Chernigovskaya M.A., Shpynev B.G., Ratovsky K.G. Meteorological effects of ionospheric disturbances from vertical radio sounding data. J. Atmos. Solar-Terr. Phys. 2015, vol. 136, pp. 235-243. DOI: 10.1016/j.jastp.2015.07.006.

Chernigovskaya M.A., Shpynev B.G., Yasyukevich A.S., Mylnikova A.A., Khabituyev D.S., Knizhova Koutska P., Kouba D., Melich I., Kozlovsky A. Ionospheric variability over Europe in winter from the ionosonde and GPS/ GLONASS data. Sovremennye problemy distantsionnogo zondirovaniya Zemli iz kosmosa [Current Problems in Remote Sensing of the Earth from Space]. 2018a, vol. 15, no. 4, pp. 295307. (In Russian).

Chernigovskaya M.A., Shpynev B.G., Ratovsky K.G., Belinskaya A.Yu., Stepanov A.E., Bychkov V.V., Grigorieva S.A., Panchenko V.A., Korenkova N.A., Mielich J. Ionospheric response to winter stratosphere/lower mesosphere jet stream in the Northern Hemisphere as derived from vertical radio sounding data. J. Atmos. Solar-Terr. Phys. 2018b, vol. 180, pp. 126-136. DOI: 10.1016/j.jastp.2017.08.033.

Danilov A.D., Laštovička J. Effects of geomagnetic storms on the ionosphere and atmosphere. Int. J. Geomagn. Aeron. 2001, vol. 2, pp. 209-224.

Deminov M.G., Deminova G.F., Zherebtsov G.A., Pirog O.M., Polekh N.M. Variability of parameters of the F2-layer maximum of the quiet midlatitude ionosphere under low solar activity: 1. Statistical properties. Geomagnetism and Aeronomy. 2011a, vol. 51, iss. 3, pp. 348355. DOI: 10.1134/ S001679321102006X.

Deminov M.G., Romanova E.B., Tashchilin A.V. Origination of $\mathrm{G}$ conditions in the ionospheric $\mathrm{F}$ region depending on solar and geomagnetic activity. Geomagnetism and Aeronomy, 2011b, vol. 51, iss. 5, pp. 669-675. DOI: 10.1134/ S0016793211050045.

Fishkova L.M. On variations of intensity of the upper atmosphere nightglow during sudden stratospheric warmings. Geomagnetizm i aeronomiya [Geomagnetism and Aeronomy]. 1978, vol. 18, no. 3. pp. 143-148. (In Russian).

Funke B., Lopez-Puertas M., Bermejo-Pantalen D., GarcaComas M., Stiller G.P., von Clarmann T., Kiefer M., Linden A. Evidence for dynamical coupling from the lower atmosphere to the thermosphere during a major stratospheric warming. Geophys. Res. Lett. 2010, L13803. DOI: 10.1029/2010GL043619.

Goncharenko L., Zhang S.-R. Ionospheric signatures of sudden stratospheric warming: ion temperature at middle latitude. Geophys. Res. Lett. 2008, vol. 35, L21103. DOI: 10.1029/ 2008GL035684.

Goncharenko L.P., Coster A.J., Chau J.L., Valladares C.E. Impact of sudden stratospheric warming on equatorial ionization anomaly. J. Geophys. Res. 2010a, vol. 115, A00C07. DOI: 10.1029/2010JA015400.

Goncharenko L.P., Chau J.L., Liu H.-L., Coster A.J. Unexpected connections between stratosphere and iono- sphere. Geophys. Res. Lett. 2010b, vol. 37, L10101. DOI: 10.1029/ 2010GL043125.

Goncharenko L.P., Hsu V.W., Brum C.G.M., Zhang S.-R., Fentzke J.T. Wave signatures in the midlatitude ionosphere during a sudden stratospheric warming of January 2010. J. Geophys. Res.: Space Phys. 2013, vol. 118, iss. 1, pp. 472487. DOI: 10.1029/2012JA018251.

Hocke K., Lainer M., Schanz A. Composite analysis of a major sudden stratospheric warming. Ann. Geophys. 2015, vol. 33, pp. 783-788. DOI: 10.5194/angeocom-33-783-2015.

Ivanov-Kholodny G.S., Nikolsky G.M. Solntse i ionosfera [The Sun and the Ionosphere]. Moscow, Nauka Publ., 1969. 466 p. (In Russian).

Khmyrov G.M., Galkin I.A., Kozlov A.V., Reinisch B.W., McElroy J., Dozois C. Exploring digisonde ionogram data with SAO-X and DIDBase. Radio Sounding and Plasma Physics. AIP Conf. Proc. 2008, vol. 974, iss. 1, pp. 175-185. DOI: 10.1063/1.2885027.

Matsuno T. A dynamical model of the stratospheric sudden warming. J. Atmos. Sci. 1971, vol. 28, pp. 1479-1494.

Medvedeva I., Ratovsky K. Effects of the 2016 February minor sudden stratospheric warming on the MLT and ionosphere over Eastern Siberia. J. Atmos. Solar-Terr. Phys. 2018, vol. 180, pp. 116-125. DOI: 10.1016/j.jastp.2017.09.007.

Medvedeva I.V., Semenov A.I., Chernigovskaya M.A., Perminov V.I. Studying manifestations of 2008-2011 sudden stratospheric warmings in East-Siberia and European Russia. Geophysica. 2012, vol. 48, no. 1-2, pp. 91-103.

Pancheva D., Mukhtarov P. Stratospheric warming: The atmospherc-stratospheric coupling paradigm. J. Atmos. Solar-Terr. Phys. 2011, vol. 73, pp. 1697-1702. DOI: 10.1016/j.jastp. 2011.03.006

Pedatella N.M., Forbes J.M. Evidence for stratosphere sudden warming-ionosphere coupling due to vertically propagating tides. Geophys. Res. Lett. 2010, vol. 37, L11104. DOI: 10.1029/2010GL043560.

Polyakova A.S., Chernigovskaya M.A., Perevalova N.P. Ionospheric effects of sudden stratospheric warmings in eastern Siberia region. J. Atmos. Solar-Terr. Phys. 2014, vol. 120, pp. 15-23. DOI: 10.1016/j.jastp.2014.08.011.

Prölss G.W. Storm-induced changes in the thermospheric composition at middle latitudes. Planet. Space Sci. 1987, vol. 35, no. 6, pp. 807-811.

Polekh N.M., Romanova E.B., Ratovsky K.G., Shi J.K., Wang X., Wang G.J. Studying the G condition occurrence in different latitudes under solar minimum: Observation and modeling. J. Atmos. Solar-Terr. Phys. 2015, vol. 130. pp. 132141. DOI: 10.1016/j.jastp.2015.06.001.

Polyakov V.M., Shchepkin L.A., Kazimirovsky E.S., Kokourov V.D. Ionosfernye protsessy [Ionospheric Processes]. Novosibirsk, Nauka Publ., 1968, 536 p. (In Russian).

Shchepkin L.A., Kushnarenko G.P., Freizon I.A., Kuznetsova G.M. Connection between electron density in the middle ionosphere and thermospheric conditions. Geomagnetizm i aeronomiya [Geomagnetism and Aeronomy]. 1997, vol. 37, no. 5, pp. 106-113. (In Russian).

Shpynev B.G., Pabcheva D., Mukhratov P., Kurkin V.I., Ratovsky K.G., Chernigovskaya M.A., Belinskaya A.Yu., Stepanov A.E. Ionosphere response over Eastern Siberia during the 2009 sudden stratospheric warming derived from data of ground based and satellite radio sounding. Sovremennye problemy distantsionnogo zondirovaniya Zemli iz kosmosa [Current Problems in Remote Sensing of the Earth from Space]. 2013, vol. 10, no. 1, pp. 153-163. (In Russian).

Shpynev B.G., Churilov S.M., Chernigovskaya M.A. Generation of waves by jet-stream instabilities in winter polar stratosphere/mesosphere. J. Atmos. Solar-Terr. Phys. 2015a, vol. 136, pp. 201-215. DOI: 10.1016/j.jastp.2015.07.005. 
Shpynev B.G., Kurkin V.I., Ratovsky K.G., Chernigovskaya M.A. Belinskaya A.Yu., Grigorieva S.A., Stepanov A.E., Bychkov V.V., Pancheva D., Mukhtarov P. High-midlatitude ionosphere response to major stratospheric warming. Earth, Planets and Space. 2015b, vol. 67, article id.18. DOI: 10.1186/s40623-015-0187-1.

Shpynev B.G., Chernigovskaya M.A., Khabituyev D.S Spectral characteristics of atmospheric waves generated by winter stratospheric jet flow of the Northern Hemisphere. Sovremennye problemy distantsionnogo zondirovaniya Zemli iz kosmosa [Current Problems in Remote Sensing of the Earth from Space]. 2016, vol. 13, no. 2, pp. 120-131. DOI: 10.21046/2070-7401-2016-13-2-120-131. (In Russian).

Sumod S.G., Pant T.K., Jose Lijo., Hossain M.M., Kumar K.K. Signature of Sudden stratospheric warming on equatorial ionosphere-termosphere system. Planet. Space Sci. 2012, vol. 63-64, pp. 49-55. DOI: 10.1016/j.pss.2011.08.005.

Vargin P.N., Medvedeva I.V. Research into temperature and dynamic conditions of the Northern Hemisphere extratropical atmosphere during the sudden stratospheric warming in winter 2012-2013. Izvestiya RAN. Fizika atmosfery $i$ okeana [Izvestiya. Atmospheric and Oceanic Physics]. 2015, vol. 51, no. 1, pp. 20-38. DOI: 10.7868/S0002351514060170. (In Russian).
Waugh D.W., Polvani L.M. Stratospheric Polar Vortices. The Stratosphere: Dynamics, Transport, and Chemistry. 2010, pp. 43-57. (Geophys. Monogr. Ser., vol. 190). DOI: 10.1029/ 2009GM000887.

Yasyukevich A.S., Chernigovskaya M.A., Mylnikova A.A., Shpynev B.G., Khabituyev D.S. Seasonal variations of the ionospheric storminess during different heliogeomagnetic conditions from GPS/GLONASS data over East Siberia and Far East. Sovremennye problemy distantsionnogo zondirovaniya Zemli iz kosmosa [Current Problems in Remote Sensing of the Earth from Space]. 2017, vol. 14, no. 4, pp. 249-262. DOI: 10.21046/20707401-2017-14-4-249-262.

Yigit E., Medvedev A. Internal wave coupling processes in Earth's atmosphere. Adv. Space Res. 2015, vol. 55, pp. 9831003. DOI: 10.1016/j.asr.2014.11.020.

Yigit E., Medvedev A.S., England S.L., Immel T.J. Simulated variability of the high-latitude thermosphere induced by small-scale gravity waves during a sudden stratospheric warming. J. Geophys. Res. 2014, vol. 119, iss. 1, pp. 357-365. DOI: $10.1002 / 2013 J A 019283$.

How to cite this article

Polekh N.M., Chernigovskaya M.A., Yakovleva O.E. On the formation of the $\mathrm{F} 1$ layer during sudden stratospheric warming events. Solar-Terrestrial Physics. 2019. Vol. 5. Iss. 3. P. 117-127. DOI: $10.12737 /$ stp-53201914. 